\title{
Análisis de intensidad de deslizamiento en función de volúmenes removidos en la Quebrada Tingoragra, distrito de Huánuco como aporte para evaluación de riesgos
}

\author{
Analysis of sliding intensity in terms of removed volumes in the Tingoragra \\ Creek, Huánuco district as contribution for risk evaluation
}

\author{
Luz Alexandra Javier Silva', Francisco Alejandro Alcántara Boza ${ }^{2}$, \\ Jorge Luis Susanibar Zevallos ${ }^{3}$
}

Recibido: Junio 2019 - Aprobado: Julio 2019

\begin{abstract}
RESUMEN
En los últimos años, el distrito de Huánuco ha presentado un crecimiento poblacional de 1.05\%, mediante un asentamiento forzoso sobre áreas inestables, incrementando la vulnerabilidad frente a eventos extremos. La forma de la superficie terrestre puede considerarse como resultante de un sistema evolutivo dentro de escalas de tiempo. Por tanto, se analizó por medio del procesamiento digital de imágenes, el volumen de la remoción en masa empleando imágenes de satélite ALOS PALSAR (2006-2019) y Landsat 5 EMT y 8 OLI (1987-2018), para establecer una relación entre la evolución del paisaje y la ocurrencia de deslizamientos por medio de perfiles topográficos.

Finalmente, se logró demostrar la diferencia entre medias de la evolución del deslizamiento de la quebrada Tingoragra en el distrito de Huánuco (2006-2019), según la clasificación de intensidad en función del volumen por deslizamientos (222,129,497 m³) para establecer un análisis del riesgo.

Palabras clave: Quebrada; susceptibilidad; deslizamiento; riesgos; sistemas de información geográfica; crecimiento urbano.

ABSTRACT

In recent years, the district of Huánuco has presented a population growth of $1.05 \%$, through a forced settlement on unstable areas, increasing vulnerability to extreme events. The shape of the earth's surface can be considered as resulting from an evolutionary system within time scales. Therefore, it is intended to analyze by means of digital image processing, mass removal volume using ALOS PALSAR satellite images (2006-2019) and Landsat 5 EMT and 8 OLI (1987-2018), to establish a relationship between the evolution of the landscape and the occurrence of landslides through topographic profiles.
\end{abstract}

Finally, it was possible to demonstrate the difference between means of the evolution of the slide of the Tingoragra creek in the district of Huánuco (2006-2019), according to the intensity classification based on the volume by landslides $\left(222,129,497 \mathrm{~m}^{3}\right)$ to establish a risk analysis.

Keywords: Creek; susceptibility; landslide; risks; geographic information systems; urban growth.

\footnotetext{
1 Geógrafa de la Universidad Nacional Mayor de San Marcos. Lima, Perú. E-mail: lualjasigeo@gmail.com

2 Ingeniero Geógrafo, docente de la Facultad de Ingeniería Geológica, Minas, Metalúrgica y Geográfica de la Universidad Nacional Mayor de San Marcos. Lima, Perú. E-mail: falcantadab@unmsm.edu.pe

3 Físico de la Universidad Nacional Mayor de San Marcos. Lima, Perú. E-mail: luis.susanibar5@gmail.com
} 


\section{INTRODUCCIÓN}

El distrito de Huánuco presenta un total de 847,714 habitantes (Instituto Nacional de Estadística e Informática [INEI], 2017). La parte norte del distrito se encuentra en un proceso de continua expansión, con un total de 16,500 habitantes, calculado a partir de proyecciones (INEI, 2015).

Los tipos de factores que intervienen en el proceso de modificación del modelado terrestre son: constantes o con poca variabilidad a lo largo del tiempo (tipo de suelo, pendiente topográfica, morfología y vegetación), y los factores variables que sufren modificaciones con cierta periodicidad (precipitación, meteorización, y acciones antrópicas). (Villacorta, Núñez, Obregón \& Tatard, 2014, Bedia, 2013 y Soeters \& Van Westen, 1996).

Los movimientos en masa son parte de los procesos denudativos que modelan el relieve de la tierra, dando inicio con la formación de una ladera natural, generado por la ocurrencia de eventos excepcionales de precipitación ocasionando deslizamientos en las cabeceras y partes medias de las quebradas (Cruden y Varnes, 1996); y es el movimiento de ladera quien describe la evolución de la inestabilidad o las etapas de evolución del movimiento desde la aparición precoz de deformaciones en el terreno, la delimitación del escarpe principal y de los escarpes menores, la delimitación de la masa movilizada y su propagación, hasta que se alcanza la estabilización o el agotamiento del proceso. (Chacón, Irigaray, El Hamdouni \& Fernández, 2006)

Según, la observación geomorfológica por un periodo de 500 años y los registros de riesgos históricos del (Instituto Geológico, Minero y Metalúrgico [INGEMMET], 2006); indican como causa la activación de la quebrada Tingoragra, y que los movimientos en masa como deslizamientos son generados de forma periódica, basados en los volúmenes de material erosionable. Por otra parte, el INDECI, 2018; determina riesgo alto para el pueblo joven Las Moras, abarcando la población asentada en los alrededores del cauce de la quebrada Tingoragra.

Por tanto, el presente estudio tiene como objetivo analizar el proceso de deslizamiento en función de volúmenes removidos utilizando las herramientas SIG (ArcGIS, AutoCAD Civil) y de teledetección (ENVI) que permiten identificar las variables de inestabilidad (20062019) para evaluar el peligro y vulnerabilidad.

La hipótesis a demostrar es, que existe diferencia entre medias del volumen removido según la intensidad del deslizamiento comprendido entre los años 2006 - 2019, según la clasificación de intensidad en función del volumen por deslizamientos, realizada por Chacón, et al., 2006; que modifica la clasificación de Ardizzone, Cardinali, Carrara, Guzzetti \& Reichenbach (2002), los volúmenes removidos para la quebrada Tingoragra del distrito de Huánuco es $>500,000 \mathrm{~m}^{3}$; donde se define una escala en función del volumen para establecer la velocidad estimada por deslizamientos con rangos: Muy Bajo $\left(<500 \mathrm{~m}^{3}\right)$, Bajo $\left(500-10000 \mathrm{~m}^{3}\right)$, Medio $\left(10000-500000 \mathrm{~m}^{3}\right)$ y Muy Alto $\left(>>500000 \mathrm{~m}^{3}\right)$. (Tabla 1).

\section{MÉTODOS}

La quebrada Tingoragra se encuentra a 2,027 m.s.n.m, ubicada en la Vertiente Oriental Andina, en la zona transicional entre la región altoandina y la selva alta; caracterizado por la presencia del valle interandino del río Huallaga limitado por montañas moderadas a abruptas, jurisdicción del distrito de Huánuco (INGEMMET, 2006) (Figura 1).

Las imágenes de satélite utilizadas corresponden a los satélites Landsat (5 TM y 8 OLI) con el Path/Row: 7/67 de los años 1987-2019; y Alos Palsar con $12.5 \mathrm{~m}$. de resolución espacial y 16 bits de resolución radiométrica, de los años 2006-2019. Las características de imágenes Landsat se encuentran por tipo de sensor, $\mathrm{N}^{\circ}$ Bandas, rango espectral, resolución espacial y resolución radiométrica se muestran en la Tabla 2

El proceso metodológico considera cuatro (4) fases: Fase de la recolección de la información, análisis y tratamiento de la información, campo y gabinete, para determinar la variación de volumen removido por procesos de deslizamientos (2006-2019), desarrollado por medio de subprocesos (Figura 2).

Para el procesamiento de imágenes Landsat utilizamos en el software ENVI 5.3, donde se aplicó la corrección radiométrica, atmosférica, con el cálculo de band ratios se extrajeron características de interés, para finalmente aplicar la herramienta density slice que permitió convertir la imagen de tonos grises en una serie de intervalos y pasarlos a formato vectorial, el procedimiento fue repetido para cada imagen de forma individual, donde la finalidad fue obtener el área del material deslizado dentro de los periodos 1987-2019.

Finalmente se creó un Modelo Cartográfico en el software ArcGIS 10.5, empleando como parámetro del geoprocesamiento inicial los archivos: DEM (Alos Palsar)

Tabla 1. Clasificación de Intensidades en función del volumen para deslizamientos

\begin{tabular}{|c|c|c|}
\hline $\mathbf{M}=\mathbf{f}($ volumen, velocidad $)$ & Velocidad estimada & Tipo de daños \\
\hline$<500$ & Baja & Sin daños a estructuras \\
\hline $500-10000$ & Moderada & Frecuentes daños y reparaciones costosas \\
\hline $10000-500000$ & Media & Daños intensos a estructuras \\
\hline$>500000$ & Alta & Evacuación difícil. Daños irreparables \\
\hline$>500000$ & Muy Alta & Destrucción total de vidas y bienes \\
\hline
\end{tabular}

Fuente. Chacón, et al.,2006. 


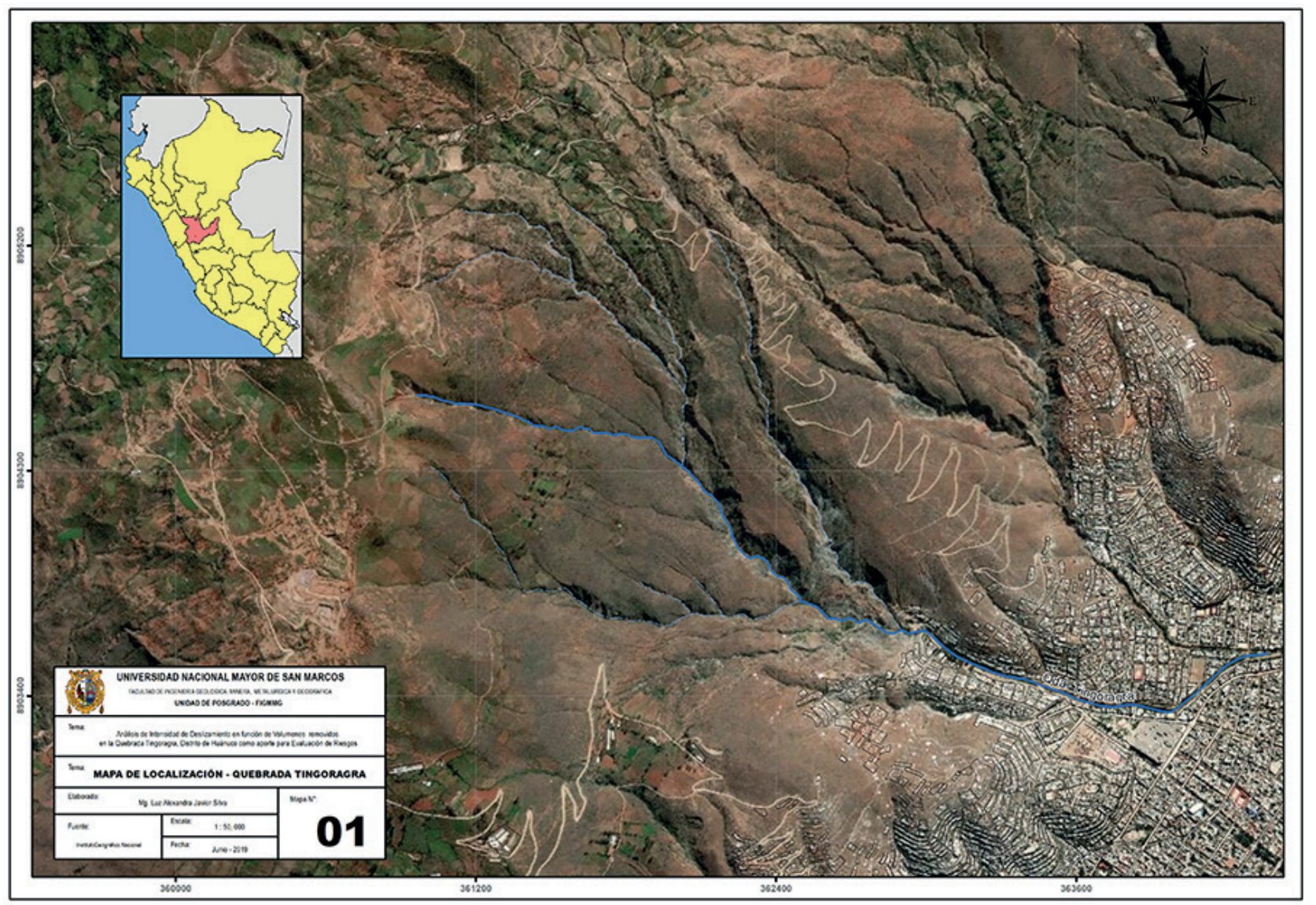

Figura 1. Mapa de Localización - Quebrada Tingoragra

Tabla 2. Características de las imágenes Landsat TM y OLI

\begin{tabular}{|c|c|c|c|c|c|}
\hline Sensor & Subsistema & $\mathrm{N}^{\circ}$ Banda & Rango Espectral $\mu \mathrm{m}$ (micrómetro) & Resolución Espacial & Resolución Radiométrica \\
\hline \multirow{7}{*}{ TM } & \multirow{4}{*}{ VNIR } & 1 & $0.45-0.52 \mu \mathrm{m}$ & \multirow{4}{*}{$30 \mathrm{~m}$} & \multirow{4}{*}{8 bits } \\
\hline & & 2 & $0.53-0.60 \mu \mathrm{m}$ & & \\
\hline & & 3 & $0.63-0.69 \mu \mathrm{m}$ & & \\
\hline & & 4 & $0.76-0.90 \mu \mathrm{m}$ & & \\
\hline & \multirow{2}{*}{ SWIR } & 5 & $1.55-1.75 \mu \mathrm{m}$ & \multirow{2}{*}{$30 \mathrm{~m}$} & \multirow{2}{*}{8 bits } \\
\hline & & 7 & $2.08-2.35 \mu \mathrm{m}$ & & \\
\hline & $\mathrm{TIR}$ & 6 & $10.7-12.3 \mu \mathrm{m}$ & $120 \mathrm{~m}$ & 8 bits \\
\hline \multirow{11}{*}{ OLI } & \multirow{5}{*}{ VNIR } & 1 & $0.435-0.451 \mu \mathrm{m}$ & \multirow{5}{*}{$30 \mathrm{~m}$} & \multirow{5}{*}{12 bits } \\
\hline & & 2 & $0.452-0.512 \mu \mathrm{m}$ & & \\
\hline & & 3 & $0.533-0.590 \mu \mathrm{m}$ & & \\
\hline & & 4 & $0.636-0.673 \mu \mathrm{m}$ & & \\
\hline & & 5 & $0.821-0.879 \mu \mathrm{m}$ & & \\
\hline & \multirow{2}{*}{ SWIR } & 6 & $1.566-1.681 \mu \mathrm{m}$ & \multirow{2}{*}{$30 \mathrm{~m}$} & \multirow{2}{*}{12 bits } \\
\hline & & 7 & 2.107-2.294 $\mu \mathrm{m}$ & & \\
\hline & PAN & 8 & $0.50-0.68 \mu \mathrm{m}$ & $15 \mathrm{~m}$ & 12 bits \\
\hline & CIRRUS & 9 & $1.36-1.38 \mu \mathrm{m}$ & $30 \mathrm{~m}$ & 12 bits \\
\hline & \multirow{2}{*}{ TIR } & 10 & $10.6-11.19 \mu \mathrm{m}$ & \multirow{2}{*}{$100 \mathrm{~m}$} & \multirow{2}{*}{12 bits } \\
\hline & & 11 & $11.50-12.51 \mu \mathrm{m}$ & & \\
\hline
\end{tabular}

Fuente. USGS, 2013 


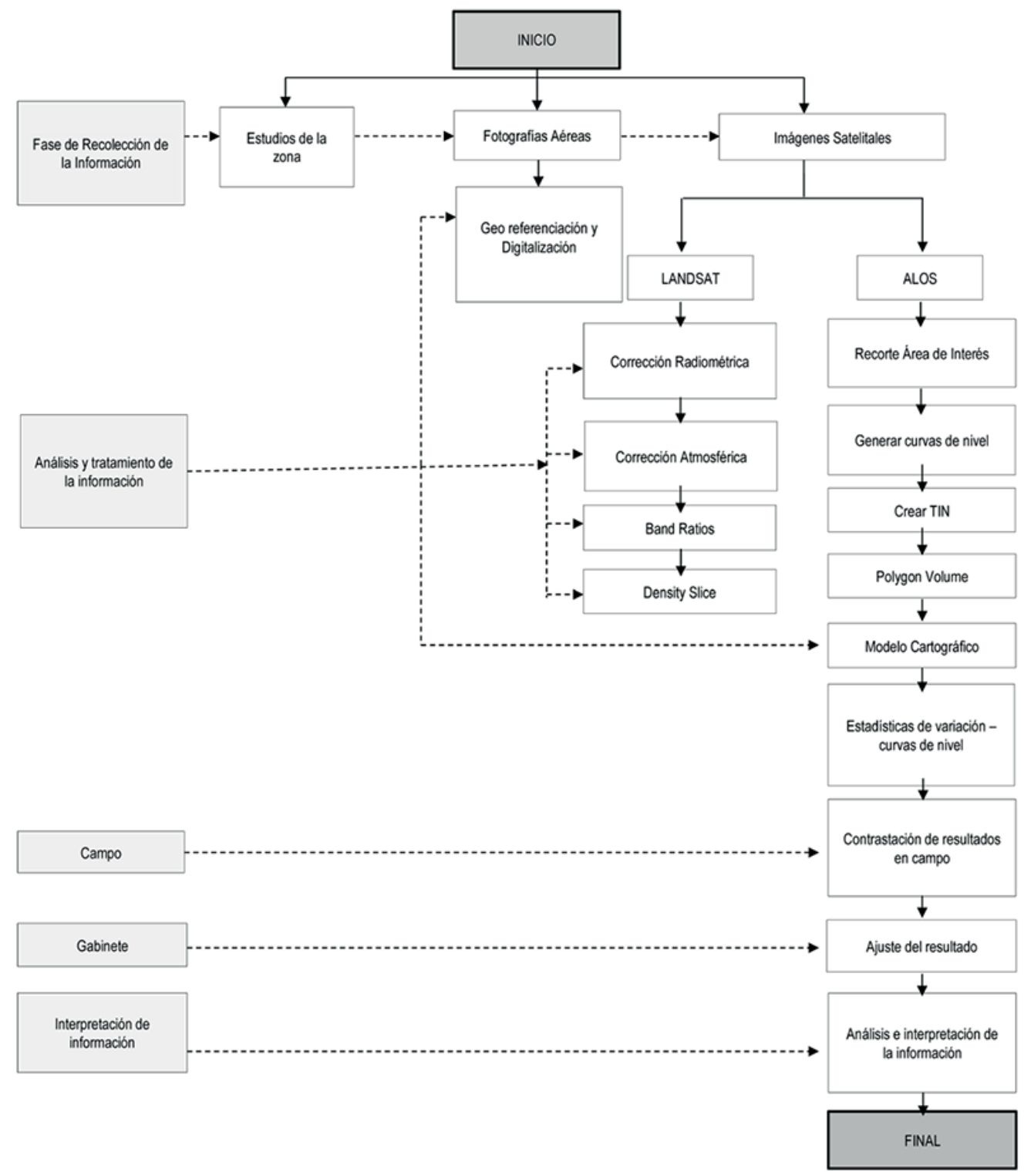

Figura 2. Flujograma de Trabajo

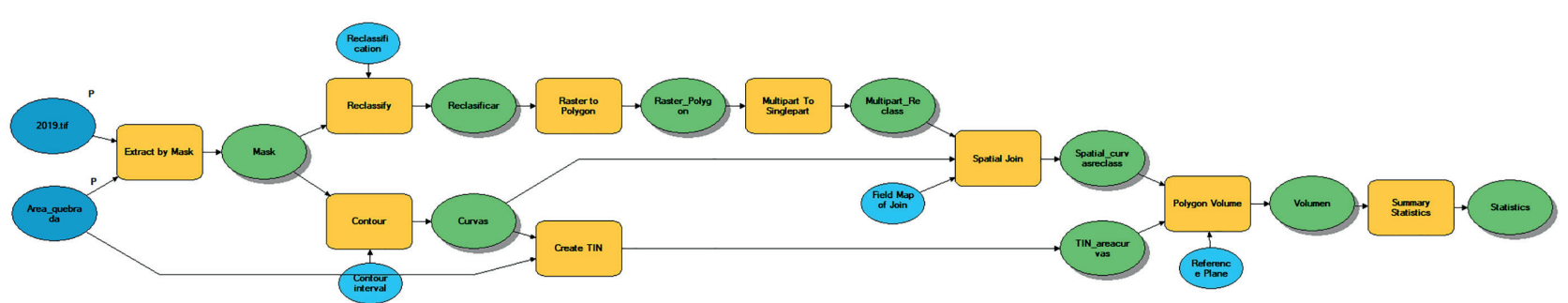

Figura 3. Modelo para el Cálculo de Volúmen de material removido

y el área de deslizamiento procesado a partir de imágenes Landsat. Como primer paso para la creación del Modelo, realizamos el recorte del área de interés con "Extract by mask", luego se realizaron dos procesos alternos: a. Reclasificación (Reclassify), conversión de ráster a polígono (Raster to Polygon) y la división de entidades a partes individuales (Multipart to singlepart), la finalidad del procedimiento (a) fue la de obtener áreas uniformes en base a alturas; b. Creación de curvas de nivel y un TIN, que son construidos mediante la triangulación de un conjunto de vértices que representa la morfología de la superficie, para la unión de los procesos (a) y (b) nos basamos en la relación espacial (Spatial Join). Finalmente, se aplicó la herramienta 'Poygon Volume' para obtener el resultado del cálculo del área volumétrica y de superficie, y para mostrar el resumen del cálculo en una tabla (Summary Statistics) (Figura 3). 


\section{RESULTADOS}

El área de deslizamiento calculado a partir de imagen de satélite muestra 25,741,868 $\mathrm{m}^{2}$ para el año 2019 (Figura 5). Se entiende por amenaza como la probabilidad de ocurrencia de deslizamientos en áreas susceptibles, como el resultado semicuantitativo del volumen removido por año considerado como Muy Alto: $>5,500,000 \mathrm{~m}^{3}$ (rojo), Alto: volumen $>3,800,000 \mathrm{~m}^{3}$ (naranja), Medio: $>1,000,000$ $3,800,000 \mathrm{~m}^{3}$ (amarillo) y los demás valores considerados como Bajo, considerado a modo de representación interanual, para la zona de estudio, utilizando el método de clasificación de datos 'Natural break', que permite clasificar campos numéricos para la simbología graduada mediante las agrupaciones naturales inherentes a los datos, caracterizado por el mejor agrupamiento de valores similares, maximizando las diferencias entre clases.

El patrón de análisis es cambiante sobre todo en la parte media y baja, sin embargo; para el año 2016 se registró una mayor actividad de deslizamiento, con precipitación anual de 494,6 $\mathrm{m}^{3}$, según datos compartidos por el SENAMHI del año 2016. (Figura 4).
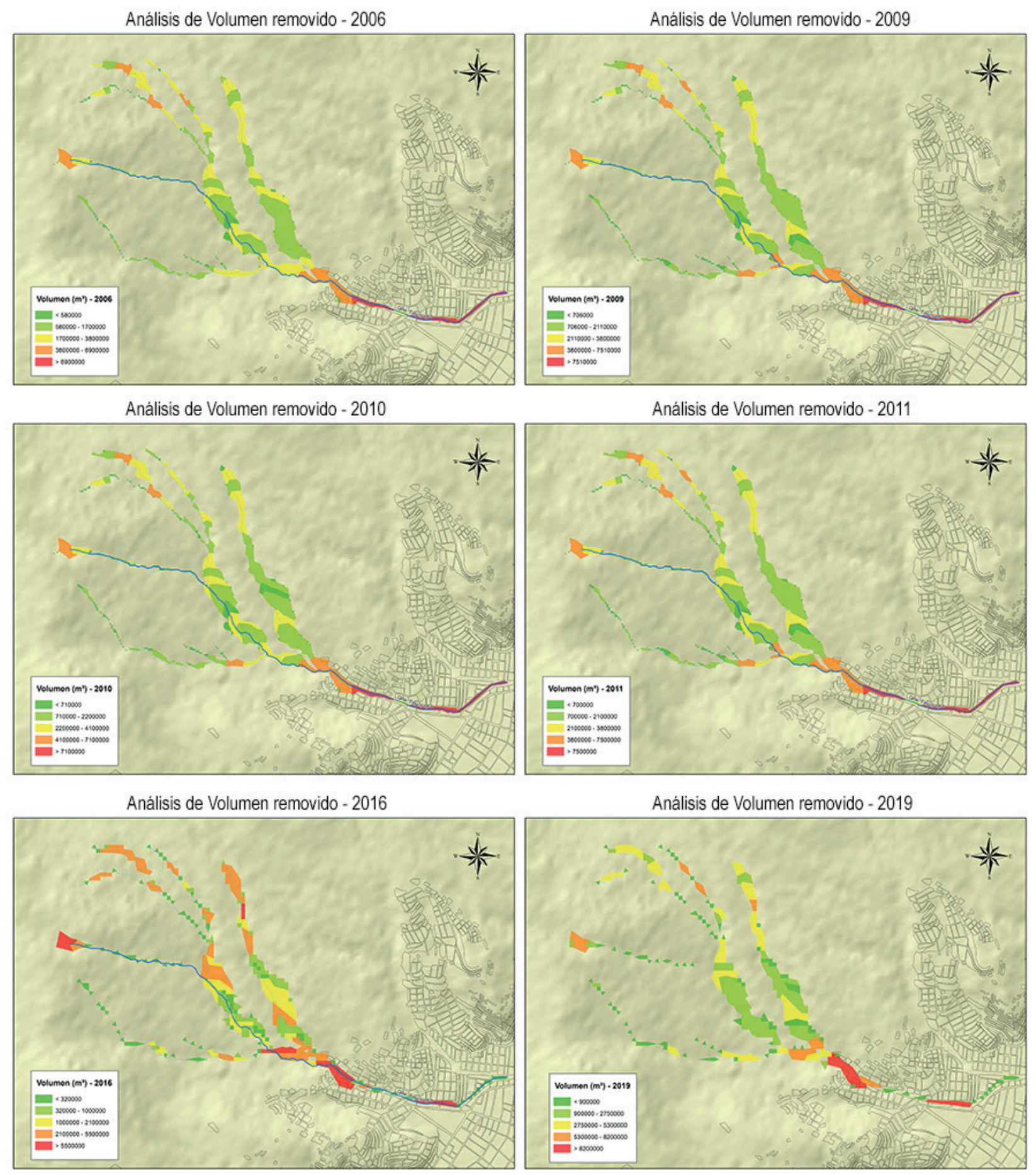

Figura 4. Análisis de Deslizamiento de material removido 2006 - 2019 
La variación interanual en base a la modificación topográfica (Figura 6) en el periodo (2006-2009) se presentó un deslizamiento de 2,668,635 $\mathrm{m}^{3}$, para los años (2010-2011) un deslizamiento de 105,756 $\mathrm{m}^{3},(2011-2016)$ fueron los años que registró mayor incremento volumétrico de remoción y (2016-2019) un volumen de $39605628 \mathrm{~m}^{3}$. (Figura 6)

La precipitación media mensual para el distrito de Huánuco $(25.7 \mathrm{~mm})$, no coincide con la producción del volumen del material deslizado en la zona, indicando que el exceso de precipitaciones acumula nivel de caudal líquido de escorrentía, generando: elevación del nivel freático, carga de fisuras y saturación; entre otro de los efectos asociados es la disminución de resistencia en zonas críticas, causando como efecto el desembalse y arrastre superficial; erosión de laderas (acumulación en pie de conos de deyección y erosión interna); el efecto de socavación (elimina zonas resistentes); y la disolución (crea cavernas y túneles), coincidiendo con lo expuesto en la investigación de (Chiroque \& Lavado, 2016 y García, 2000). La morfología física observada, para el cauce en las cárcavas varía en $15^{\circ}-22^{\circ}$ (parte media a superior) y $3^{\circ}-6^{\circ}$ (parte inferior) con cauces angostos aproximadamente 15$22 \mathrm{~m}$. (Figura 5).

Los eventos de remoción en masa de mayor envergadura no necesariamente se generaron en inviernos, ni son directamente asociados a las precipitaciones intensas como lo indica Gómez, Guadalupe, Bedia \& Chacón, 2015 y Sánchez, Serrano, Sangermán, Navarro, Vera, Cuevas \& Macías, 2011,sino que están asociados a la variación constante entre precipitación (suelo sometido a ciclos de humedecimiento); y la temperatura (modifica la humedad del suelo por el efecto de secado), produciendo efectos disruptivos. Según Datos históricos del SENAMHI, el sistema Köppen-Geiger clasifica el clima de Huánuco como BSh (estepa local). En el año 2016 se registró la mayor precipitación $(36.2 \mathrm{~mm}$ ) y la mayor temperatura (31 $\left.{ }^{\circ} \mathrm{C}\right)$, lo que provocó un deslizamiento volumétrico mayor, modificando el relieve en relación a la altura a diferencia del resto de los años analizados, lo que indica la relación directa entre precipitación (variable desencadenante principal) y temperatura (Figura 8).
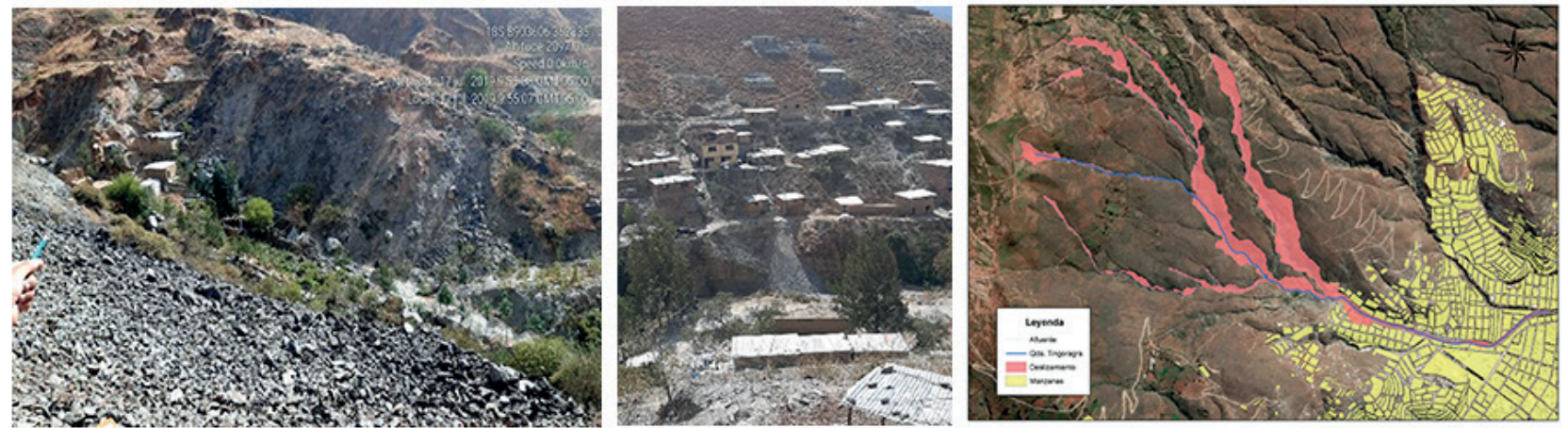

Figura 5. Deslizamiento de material removido 2019

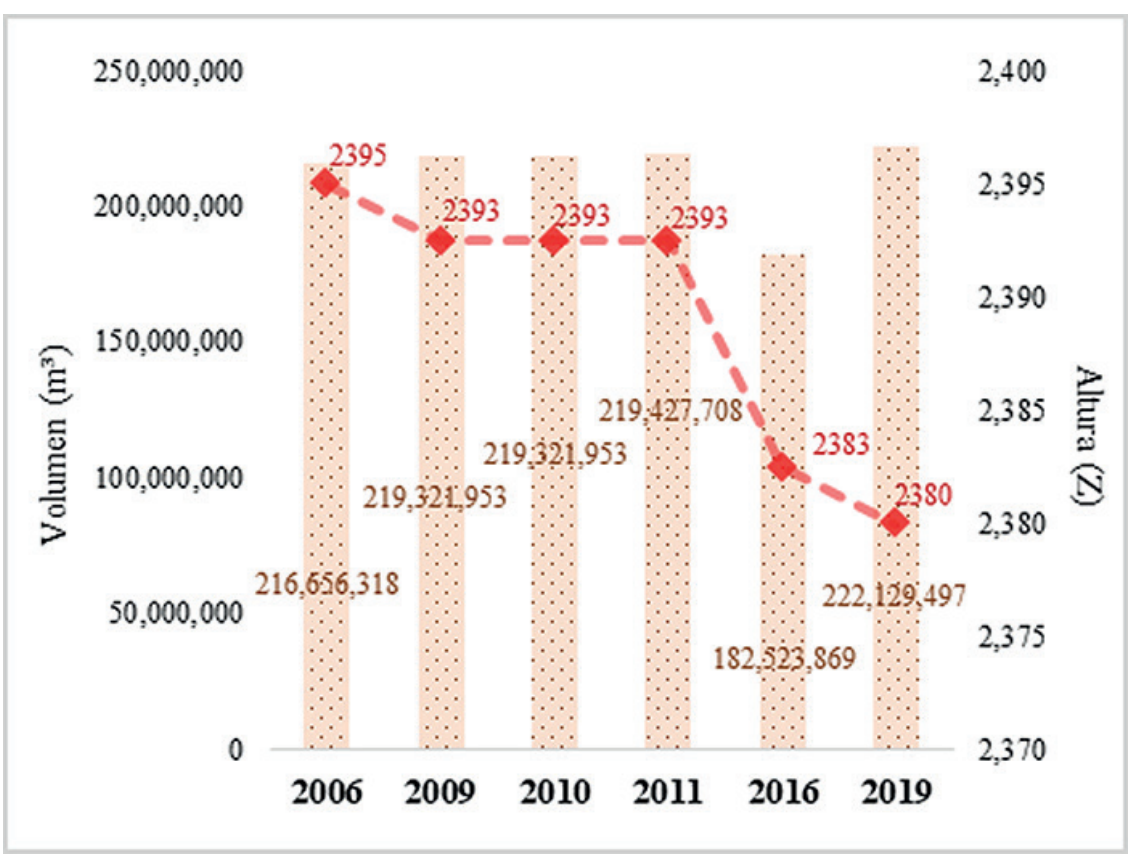

Figura 6. Variación de Volumen $\left(\mathrm{m}^{3}\right)$ de Deslizamiento removido 2006 - 2019 
Por otro lado, Hauser (1985) establece que las lluvias con umbral de $60 \mathrm{~mm} /$ día en la zona preandina, generan eventos de remoción en masa, asociadas a las características mecánicas de los suelos superficiales como de las rocas que experimentan resecamiento por aumento de la temperatura, y generándose un microfracturamiento superficial ante la presencia de lluvias repentinas e intensas; se ha comprobado que para la zona de estudio el peligro de categoría es alto, según el análisis realizado por el Centro Nacional de Estimación, Prevención y Reducción del Riesgo de Desastres [CENEPRED], 2011. La categoría de lluvia para la ciudad de Huánuco es de "extremadamente lluvioso" (umbral > $30.9 \mathrm{~mm} /$ día), comparado según umbrales de precipitación absoluta establecida por la subdirección de predicción climática del Servicio Nacional de Meteorología e Hidrología del Perú [SENAMHI], 2014.
La Figura 9 compara valores interanuales (20062019), con lo establecido por Chacón, et al., 2006; dando como resultado valores $>500,000 \mathrm{~m}^{3}$, aduciendo la característica de volumen removido "Muy Alto", en particular para los años 2011-2016, (Figura 6) se observa un cambio brusco de pendiente entre estos años.

La capacidad destructiva o intensidad de los deslizamientos se encuentran como relación entre masa movilizada y velocidad alcanzada, combinando dimensiones espaciales y temporales, en contraste con Chacón, et al., 2006 y Valdivia \& Núñez, 2004; para evaluar los daños futuros dependerá de la presencia de elementos del territorio en el curso del volumen deslizado (6 manzanas, 120 predios).

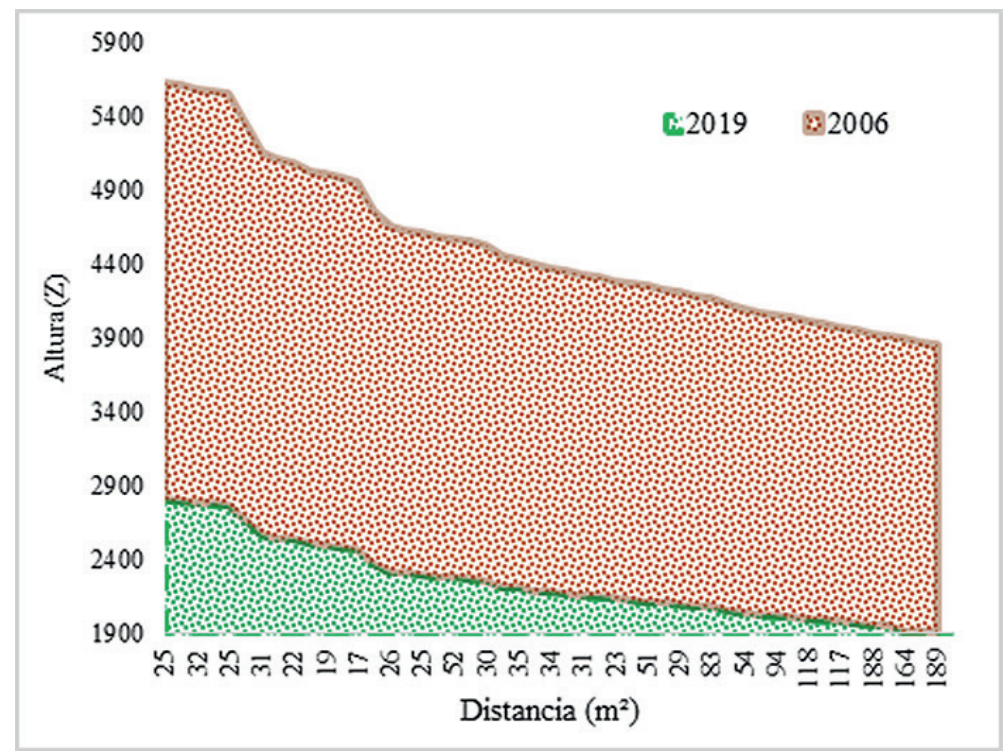

Figura 7. Perfil Topográfico Longitudinal (2006-2019)

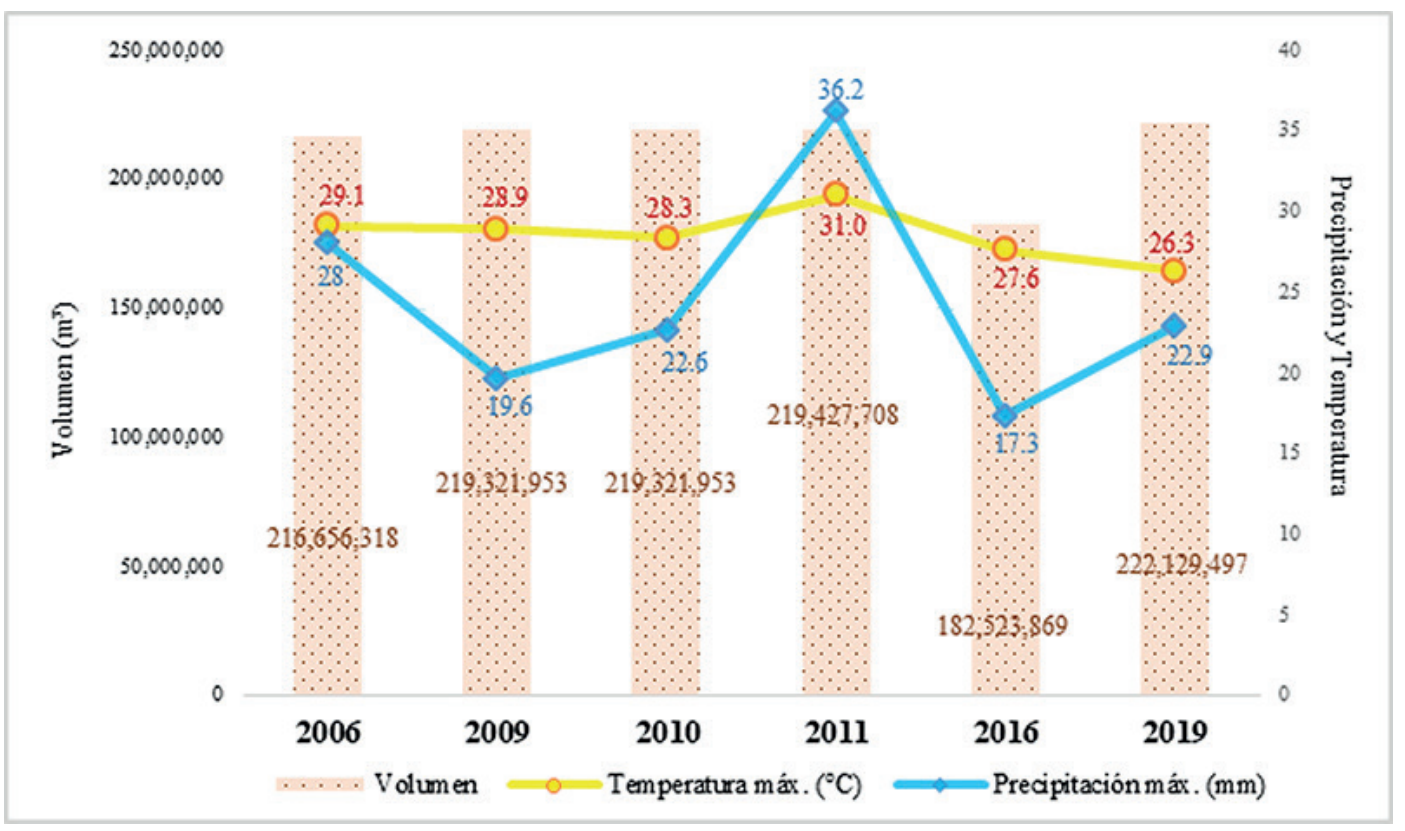

Figura 8. Patrón del volumen removido vs temperatura y precipitación 


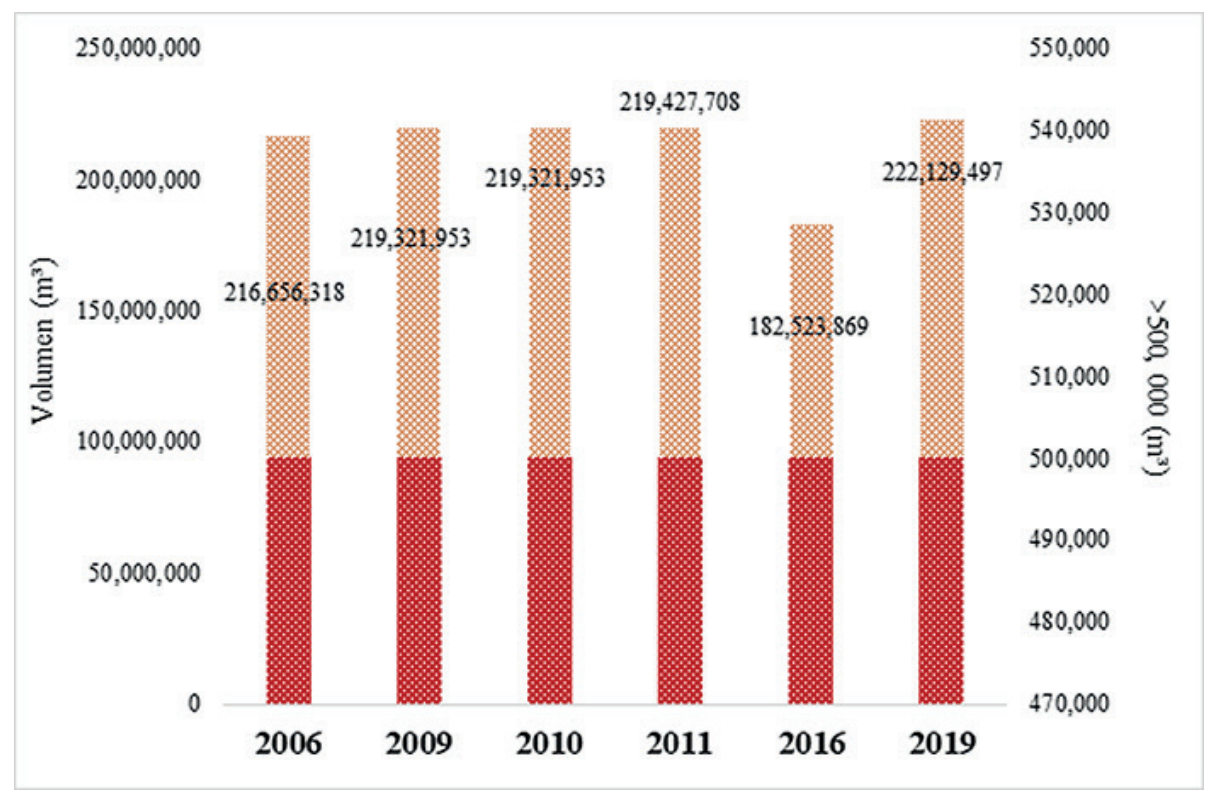

Figura 9. Comparación Volumétrica (2006-2019)

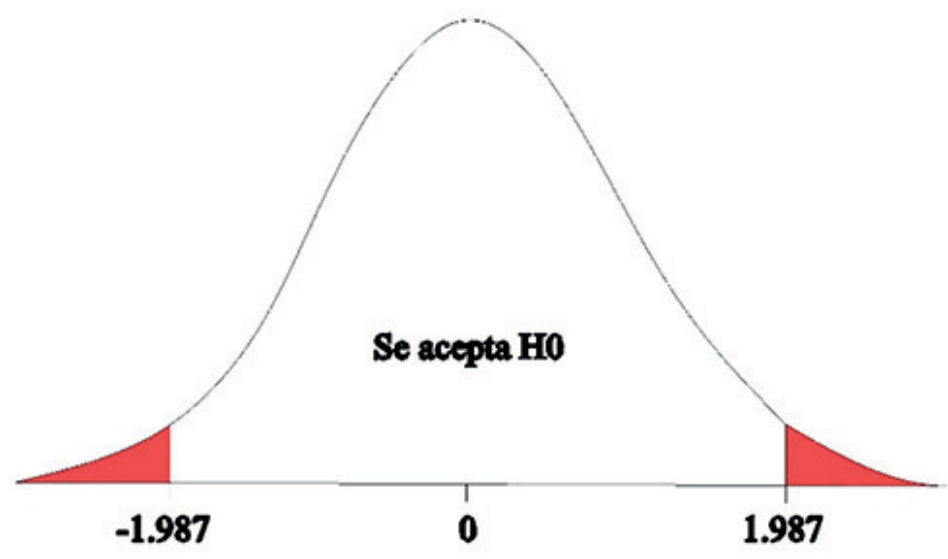

Figura 10. Gráfico T-Student

La hipótesis planteada para la investigación $\mathrm{H} 1$ : "Existe diferencia entre medias del volumen removido según la intensidad del deslizamiento comprendido entre los años 2006 - 2019)" frente a una hipótesis nula H0: "No existe diferencia entre medias del volumen removido según la intensidad del deslizamiento comprendido entre los años 2006 - 2019)", se procedió a comprobar por medio de los valores de distribución T-Student que permitió examinar las diferencias entre dos muestras (2006-2019) independientes de distribución normal y homogeneidad en sus varianzas, donde se obtuvo el valor de T-Student tabulada (1.987) y un $\mathrm{p}$ valor $<0.05$, indicando el rechazo de H0 y la aceptación de H1, por encontrarse dentro de la zona de rechazo (Ver Figura 10).

\section{CONCLUSIONES}

- La intensidad del deslizamiento comprendido entre los años 2006-2019 en función de volúmenes removidos para la quebrada Tingoragra del distrito de Huánuco es 212,730,216 m³ , promovido por cambios constantes entre lluvias y temperaturas altas generando microfracturamiento superficial del suelo.

- La variación del material deslizado entre los años (2006-2019) indica un 20.07\%, desembocando y provocando colmatación del río Huallaga, como consecuencia inundación en zonas bajas cercanas al río, y considerándose una categoría de riesgo alto, siendo una amenaza latente para el asentamiento humano Las Moras Alta

- El análisis metodológico puede aplicarse en áreas que respondan a similares factores detonantes (lluvias constantes y temperaturas altas); y condicionantes (tipo de suelo, pendiente, geomorfología y geología), para alcanzar una aproximación del comportamiento del fenómeno $\mathrm{y}$ proceder a elaborar informes de peligro y vulnerabilidad para finalmente establecer cálculos de riesgos. 


\section{AGRADECIMIENTOS}

Agradecer a las personas e instituciones que hicieron posible el desarrollo de la investigación proporcionando la información necesaria para el análisis y procesamiento; y a la Revista del Instituto de Investigación de la Facultad de Ingeniería Geológica, Minera, Metalúrgica y Geográfica de la Universidad Nacional Mayor de San Marcos por permitir la divulgación académica.

\section{REFERENCIAS BIBLIOGRÁFICAS}

Ardizzone F., Cardinali M., Carrara A., Guzzetti F., Reichenbach P. (2002). Impact of mapping errors on the reliability of landslide hazard maps. Natural Hazards and Earth System Sciences. SciVal Topic Prominence, 3-14. DOI: https://doi. org/10.5194/nhess-2-3-2002

Bedia G. Ciro. (2013). Aspectos geomorfológicos del deslizamiento de Punta Colorada, Valle de Majes - Arequipa. Revista del Instituto de Investigación FIGMMG - UNMSM, 17-27. Recuperado de https://revistasinvestigacion.unmsm. edu.pe/index.php/iigeo/article/view/3440

Cardinali, M.; Reichenbach, P.; Guzzetti, F.; Ardizzone, F.; Antonini, G.; Galli, M.; Cacciano, M.; Castellani, M.and Salvati, P. (2002). A geomorphological approach to the estimation of landslide hazards and risks in Umbria, Central Italy. Natural Hazards and Earth System Sciences. EGS 57-72. Recuperado de https://hal.archives-ouvertes.fr/hal00301559

CENEPRED. (2011). Manual para la Evaluación de Riesgos originados por Fenómenos Naturales. Recuperado de https://www.cenepred.gob.pe/web/wp-content/uploads/ Guia_Manuales/Manual-Evaluacion-de-Riesgos_v2.pdf

Chacón, J.; El Hamdouni, R.; Irigaray, C. and Fernández, T. (2006). Engineering geology maps: Landslides and GIS. Bulletin of Engineering Geology and Environment. Springer Verlag, 341-411. https://doi.org/10.1007/s10064-006-0064-z

Chiroque Cristhian y Lavado Héctor. (2016). Aspectos geológicos y geodinámicos de flujos aluvionales en la quebrada Jicamarca y análisis de la vulnerabilidad para la implementación de un Sistema de Alerta Temprana (SAT) en el centro poblado Cajamarquilla. Revista del Instituto de Investigación FIGMMG-UNMSM, 47-55. Recuperado de https://revistasinvestigacion.unmsm.edu.pe/index.php/ iigeo/article/view/13567

Cruden, D.M., Varnes, D.J. (1996). Landslide types and processes. Transportation Research Board, 36-75. Recuperado de http://onlinepubs.trb.org/Onlinepubs/sr/ sr247/sr247-003.pdf

García Gonzáles, Verónica Patricia. (2000). Fenómenos de remociones en masa asociados a la ocurrencia de anomalías atmosféricas, Santiago Oriente. Santiago: Universidad de Chile. Tesis para optar título profesional de Ingeniería Geológica.
Gómez, Guadalupe, Bedia \& Chacón. (2015). Evaluación geodinámica y modelamiento geotécnico del deslizamiento de Madrigal-Arequipa. Revista del Instituto de Investigación FIGMMG-UNMSM, 49-56. Recuperado de https://revistasinvestigacion.unmsm.edu.pe/index.php/ iigeo/article/view/14165

Hauser, A. (1985). Flujos de barro en la zona preandina de la Región Metropolitana: Características, causas, efectos, riesgos y medidas preventivas. Revista Geológica de Chile, 75-92. Revista Geológica de Chile, 75-92. DOI: http:// dx.doi.org/10.5027/andgeoV12n1-a06

INDECI. (2018). Plan de Operaciones de Emergencias Regional 2018. Lima. Recuperado de http://sinpad.indeci.gob.pe/ UploadPortalSINPAD/PNOE.pdf

INEI. (2015). Población 2000 - 2015. Lima. Recuperado de https://proyectos.inei.gob.pe/web/poblacion/

INEI. (2017). Censos Nacionales 2017: XII de población, VII de vivienda y III de comunidades indígenas. Lima. Recuperado de https://www.inei.gob.pe/media/MenuRecursivo/ publicaciones_digitales/Est/Lib1539/libro.pdf

INGEMMET. (2006). Movimientos en Masa que Afectan a la Ciudad de Huánuco: Quebradas Jactay, Tingoragra - La Florida y Llicua. Lima. Recuperado de: https://repositorio. ingemmet.gob.pe/handle/ingemmet/238\#files

Sánchez Núñez Manuel, S. F. (2011). Eventos hidrometeorológicos extremos y desastres en comunidades rurales y urbanas en Motozintla, Chiapas. 167-181. Recuperado de http://www. scielo.org.mx/pdf/remexca/v2nspe2/v2spe2a1.pdf

SENAMHI. (2014). Estimación de Umbrales de precipitaciones extremas para la estimación de avisos meteorológicos. Recuperado de https://www.senamhi.gob.pe/load/ file/01402SENA-6.pdf

Servicio Geológico de los Estados Unidos, USGS. (2013). Landsat 8: U.S. Geological Survey Fact Sheet. U.S.A. DOI: https://doi.org/10.3133/fs20153081

Soeters, R. and Van Westen, C.J. (1996). Slope instability recognition, analysis and zonation. Transportation Research Board, 129-177. Recuperado de http://onlinepubs.trb.org/ Onlinepubs/sr/sr247/sr247-008.pdf

Valdivia Fernández Helga \& NúñezAto Daniel. (2004). Evaluación del Riesgo Ambiental de tipo físico natural y su relación con el Planeamiento Urbano.Caso: Distrito de Comas. Revista del Instituto de Investigación FIGMMG-UNMSM, 45-57. Revista del Instituto de Investigación FIGMMG-UNMSM, 45-57. Recuperado de https://revistasinvestigacion.unmsm. edu.pe/index.php/iigeo/article/view/516

Villacorta Sandra, Núñez Segundo, Obregón Christian \& Tatard Lucile. (2014). Modelo de Susceptibilidad por Movimientos en Masa en Lima Metropolitana y el Callao. Revista del Instituto de Investigación de la FIGMMG - UNMSM, 125129. Recuperado de https://revistasinvestigacion.unmsm. edu.pe/index.php/iigeo/article/view/11511. 
